\title{
A Persuasive Technology for Managing Waste Disposal through Smart Trash Bin and Waste Disposal Tracker
}

\author{
Oscar Karnalim ${ }^{1 *}$, Oscar Wongso ${ }^{1}$, Vincent Elbert Budiman ${ }^{1}$, Felix Christian Jonathan ${ }^{1}$, Bertha \\ Alan Manuel ${ }^{1}$, Marlina ${ }^{1}$ \\ ${ }^{1}$ Faculty of Information Technology, Maranathan Christian University \\ Jalan Prof. Drg. Surya Sumantri No.65, Sukawarna, Bandung, West Java, Indonesia \\ *oscar.karnalim@it.maranatha.edu
}

\begin{abstract}
Waste management issue is a relevant topic that had been focused on many persuasive technologies. This issue is not only related to getting disposed of waste in proper places but also reducing waste disposal volume. This paper proposes a persuasive system that aims both goals by providing a smart trash bin and waste disposal tracker. The smart trash bin is an IoT-featured trash bin whereas waste disposal tracker is a mobile application which can record user daily waste disposal volume statistic. Based on the evaluation, our proposed system has achieved both goals. Additionally, it also solves several impediments such as incapability of moral background to encourage people to dispose waste on the trash bin, boring and monotonous waste disposal activity, and discouragement for disposing waste due to full trash bin. In order to attract people, our system includes attractive mechanisms such as playful experience, reflective experience, and gamification. Playful experience is applied to a smart trash bin, whereas the other two are applied to the waste disposal tracker.
\end{abstract}

Keywords: persuasive system; waste disposal; smart trash bin; waste disposal tracker

\section{INTRODUCTION}

$\mathbf{P}$ ersuasive technology is an HCI field that facilitates persuasive interaction in order to change people's attitudes or behaviors [1]. This technology is often used for maintaining environmental sustainability by making people aware of the consequences of their everyday actions toward the environment. Most recent works in this domain are focused on waste disposal management issues since the solution to this issue is easy to understand and apply, even for common people.

Many recent works about persuasive technology for dealing with waste disposal management issues are focused on two main goals: 1) getting disposed waste on proper places, and 2) reducing waste disposal volume. When encouraging people to dispose of waste in proper places (e.g., trash bin), most technologies try to make waste disposal tasks more enjoyable by applying playful experience or even gamification [2]. These mechanisms are expected to attract people to dispose of waste in a particular place without being bored. On the other hand, reducing waste disposal volume is typically achieved by enhancing people's awareness about their daily disposed waste. For example, daily weighing waste produced per house[3] or detecting waste distribution among particular areas [4]. Yet, these kinds of implementations are less encouraging for common people. 
Even though both goals in waste disposal management issues are equally important, most recent works are only explicitly focused on either one of them. Thus, this paper proposes a persuasive technology that aims to achieve both goals. Our proposed system consists of two components, which are smart trash bin and waste, disposal tracker. Both components are connected and interact with each other through the Internet. Smart trash bin design includes attractive design, appealing sound effects, trash-o-meter, and interactive waste disposal mechanism. On the contrary, a waste disposal tracker is implemented as a mobile application to record daily waste disposal volume. It consists of several awareness-based features such as daily waste disposal statistics, manual waste disposal data addition, interactive waste disposal data addition, and awareness-based gamification. The latter feature is intended to engage users and make them keep using our application. Additionally, our approach also enables users to record their waste disposal behavior on both smart trash bin and regular trash bin. As we know, a regular trash bin is commonly ignored in most recent works. They only focused on their designated smart trash bin instead.

\section{LITERATURE REVIEW}

When dealing with waste disposal management issues, all objectives can only be achieved by involving public participation in voluntary activities. Forcing people to change their behavior through the rules will not change their original nature. Instead, most people will only do the correct behavior when seen in public and still doing their usual behavior when no one sees them. Thus, persuasive technology is introduced to solve this problem since it may change people's attitudes and behavior without forcing them to do so [5].

There are several persuasive technologies which are focused on changing people behavior toward waste disposal management issue. Berenguer et al. connect a modified trash bin with an LCD screen that shows an emoticon [6]. That emoticon will change from poker face into happy each time a bottle is fed to the targeted smart trash bin. This playful experience is intended to make waste disposal more enjoyable. Trashcan Arcade (Bottle Bank Arcade Machine, n.d.) and Trashcan Long-hole (The World's Deepest Bin, n.d.) also have similar intentions by giving user playful experiences such as free play or unique sound effect. Despite the fact that featuring playful experience on waste disposal mechanisms may encourage people to dispose of waste in proper places, this mechanism may suffer an additional drawback. People may dispose of more waste in order to experience the playfulness.

Paulos \& Jenkins utilize using a similar approach with playfulness-based persuasive technologies [7]. Yet, they focus on reflective experience instead of a playful one. They develop JetSam, a trash bin that can project its content as a 2D image on the floor. This projected image is intended to make people aware of waste disposal as an effect of urban life. By enhancing awareness, people are implicitly encouraged to getting waste in proper places. However, this mechanism only affects people implicitly, which may be insignificant to common people.

More explicitly, a reflective-based mechanism is also applied by Cleanly [4], which visualizes the anonymous user model about location, preferences, and habits in the context of waste disposal. Their system utilized networked smart trash bins, which can recognize user contribution through user cell phones or Bluetooth MAC address, or RFID augmented badge. User contribution is then represented anonymously as a smiley face on each user entity. Even though Cleanly may encourage people to dispose of waste in proper places, this system is heavily dependent on their smart trash bins, which are only placed in a particular area.

Thieme et al. designed BinCam, a persuasive social system to motivate behavioral change in food waste and recycling habits [8]. In other words, this system also aims to reduce waste disposal volume. BinCam consists of three components: a trash bin with a smartphone embedded on it, a Facebook application, and a crowd-sourcing service. Each time waste is disposed on a trash bin by opening its lid. The smartphone will automatically take bin content like a photo and upload it to a crowd-sourcing service. After the number of food waste in that photo is counted, uploaded photos will be posted on Facebook application, and its number of food waste will be converted as a score for gamification purposes. Although this mechanism enhances people's awareness about their waste and implicitly encourage people to reduce waste disposal volume, seeing other people waste on social 
media may be uncomfortable for most people. Additionally, this system also can only be found on private places such as residential houses and apartment rooms.

Gartland \& Piasek design an interactive trash bin that can weigh its waste [3]. Waste weight and its financial cost are then displayed on a touch screen monitor, which is connected through Wi-Fi. Moreover, a touch screen monitor also displays further information about how general waste can be reduced. This system aims to encourage people to reduce their own waste by visualizing the financial benefits of producing less waste. Yet, this system is only effective in particular regions that encourage people to pay their disposed waste. Additionally, it also cannot encourage people to change their behavior in public places since the user will not gain benefits from disposed waste on the public.

Lessel et al. aim to get disposed of waste in proper places and reduce waste disposal volume. The first goal is achieved with a gamified smart trash bin, whereas the latter one is achieved with a waste classification mobile game [9]. Since their approach involves sorting waste for recycling, each trash bin is split into three sub-bins where each sub-bin represents a specific waste type. Their trash bins are placed on several public areas where each area represents a community (e.g., faculty, department, or division). Each time waste is disposed to a trash bin, a photo of disposed waste will be taken, and its waste type will be checked. If disposed waste is placed on the correct sub-bin, some points will be given to a community that is represented by that trash bin. In order to determine the correct bin for each waste, their system utilizes a waste classification mobile game where each user is asked to classify waste based on their photos. This mobile game does not only facilitate automatic waste classification but also enhances user awareness about waste type. A high awareness level about waste type is expected to support recycling for reducing waste disposal volume. However, this system suffers two drawbacks which are: this mechanism is community-based so that it is unable to record personal behavior, and it can only be found in public places.

In order to gain broader view about the differences between existing persuasive approaches, their comparison can be seen in Table I. BE stands for Berengueres et al. approach, TA stands for Trash Arcade, TL stands for Trash Long-Hole, CL stands for Cleanly, PJ stands for Paulos \& Jenkins approach, TE stands for Thieme et al. approach, GP stands for Gartland \& Piasek approach, and LE stands for Lessel et al. approach. As seen in Table I, most approaches only explicitly focus on either one of two goals, getting disposed waste on proper places or reducing waste disposal volume. The only approach which aims both goals is the LE approach. Furthermore, most recent works implement either playful experience, reflective experience, or even gamification to attract user attention. This mechanism may vary from displaying simple emoticon to a complex and challenging game. From the target perspective, not all approaches target the public since deeper reflective experience can only be achieved by having ownership of the targeted area [4]. As examples, TE and GP only target residential houses. Among all recent works, CL is the only approach that enables a user to record their personal behavior about waste management. Yet, their approach cannot record user contribution in a regular trash bin.

Our proposed approach tries to combine most benefits provided by other approaches. In goal perspective, our approach tries to combine both goals. People are encouraged to get disposed of waste in proper places and reducing their waste disposal volume. The first goal is intended to be achieved by smart trash bin features, whereas the latter one is intended to be achieved by a waste disposal tracker. Waste disposal trackers reduce waste disposal volume by enhancing people's awareness about their daily waste disposal volume. It visualizes daily waste disposal volume in which data are recorded through interactive or manual addition (interactive addition only works with smart trash bin whereas manual addition works even for regular trash bin). Additionally, it also warns users when their disposed waste is unusually higher than other users. 
TABLE I

PERSUASIVE SYSTEM COMPARISON

\begin{tabular}{lcccccccc}
\hline \multicolumn{1}{c}{ Variable } & BE & TA & TL & PJ & CL & TE & GP & LE \\
\hline Goal 1: getting disposed waste on proper places & $\sqrt{ }$ & $\sqrt{ }$ & $\sqrt{ }$ & & $\sqrt{ }$ & & & $\sqrt{ }$ \\
Goal 2: reducing waste disposal volume & & & & $\sqrt{ }$ & & $\sqrt{ }$ & $\sqrt{ }$ & $\sqrt{ }$ \\
Implement playful experience & $\sqrt{ }$ & $\sqrt{ }$ & $\sqrt{ }$ & & & & & \\
Implement reflective experience & & & & $\sqrt{ }$ & $\sqrt{ }$ & $\sqrt{ }$ & $\sqrt{ }$ & \\
Implement gamification & & & & & $\sqrt{ }$ & $\sqrt{ }$ & & $\sqrt{ }$ \\
Target public & $\sqrt{ }$ & $\sqrt{ }$ & $\sqrt{ }$ & $\sqrt{ }$ & $\sqrt{ }$ & & & $\sqrt{ }$ \\
Record personal behavior & & & & & $\sqrt{ }$ & & & \\
\hline
\end{tabular}

In order to attract people's attention, our system applies playful experience, reflective experience, and gamification at once. Playful experience is represented on our smart trash bin based on its visual appearance, appealing sound, and interactive waste disposal data addition; reflective experience is represented as daily user statistic and warning provided on our waste disposal tracker, and gamification is represented as hidden achievements and points on our waste disposal tracker. Our system targets both public and private area, public area is targeted by smart trash bin whereas the private one is targeted by waste disposal tracker.

\section{PRELIMINARY SURVEY}

A preliminary survey is conducted to prove the existence of assumed problems and determine several thresholds about daily waste disposal volume. This survey is given to 64 undergraduate students (53 males and 11 females) who are taking a short semester in the Faculty of Information Technology, Maranatha Christian University. At the first part of the survey, the respondent is asked to give their opinion about our assumed problems. Their opinion is represented on a 5-point Likert scale where 1 represents strongly disagree, and 5 represents strongly agree. In the second part, the respondent is asked to give several constants that represent their daily waste disposal volume. However, since most people do not know their waste volume accurately in kilograms, our proposed system measurement unit is based on the simplest measurement, the number of waste. The detail of our survey and its result can be seen in Table II and Table III. Table II represents the first part of our survey, whereas Table III represents the second one.

Based on Table II, there are three assumed problems that are asked to respondents. Q1 and Q3 tend to be agreed by our respondents since both of them are scored higher than 3.5 (tends to agree). Thus, it can be claimed that moral background is not sufficient to encourage people to dispose of waste in the trash bin, and a full trash bin tends to discourage people from disposing of waste in the trash bin. After further investigation, Q3 is agreed by most respondents since most people are disappointed when they open trash bin lid only to see that it is already full. Among all statements, only Q2 yields lower results than 3.5. It only yields 3.234, which means our respondents tend to be neutral about that statement. When investigated further, we have discovered that most respondents find waste disposal activity is a compulsory task as a human being. Thus, its boredom and monotonous should not be measured. However, its result is limited to undergraduate students who commonly have high moral background. In public, there is a various level of moral background, and some of them may have a lower moral background. Hence waste disposal activity may be boring and monotonous for them. Regarding our assumed problems, our proposed system also implements several features as a solution, such as an attractive mechanism to handle Q1 and Q2; and trash-o-meter to handle Q3.

When determining thresholds, all survey questions are related to the number of waste disposed of per day. These questions and results can be seen in Table III. T1 and T2 are utilized to measure the number of disposed of waste per day per person. T3 and T4 are quite similar to T1 and T2 except that they limit their coverage only 
on Grha Widya Maranatha (GWM) $8^{\text {th }}$ floor, our development environment where our smart trash bin will be placed. As seen in Table III, disposed of waste per day is about 5 to 10 , wherein 2.405 to 6.405 of them are disposed on our development environment. These thresholds are then utilized in personal statistics, warning mechanisms, and gamification on our waste disposal tracker. T1 and T2 are considered as an overall threshold, whereas T3 and T4 are considered as smart trash bin threshold (the only count disposed waste on smart trash bin).

TABLE II

ASSUMED PROBLEM SURVEY

\begin{tabular}{llc}
\hline ID & Problem & Average Result \\
\hline Q1 & Moral background is not sufficient to encourage people for disposing waste on trash bin & 3.672 \\
Q2 & Waste disposal activity is boring and monotonous & 3.234 \\
Q3 & Full trash bin tends to discourage people for disposing waste on trash bin & 3.922 \\
\hline
\end{tabular}

TABLE III

THRESHOLD SURVEY

\begin{tabular}{lll}
\hline ID & \multicolumn{1}{c}{ Statement } & Average Result \\
\hline T1 & Minimum number of waste disposed per day & 5 \\
T2 & Maximum number of waste disposed per day & 10 \\
T3 & Minimum number of waste disposed on Grha Widya Maranatha $(\mathrm{GWM}) 8^{\text {th }}$ floor per day & 2.405 \\
T4 & Maximum number of waste disposed on Grha Widya Maranatha $(\mathrm{GWM}) 8^{\text {th }}$ floor per day & 6.405 \\
\hline
\end{tabular}

\section{SYSTEM DESIGN}

The proposed persuasive system consists of a smart trash bin, a mobile application called waste disposal tracker, and a server to connect the smart trash bin with a mobile application. However, since our server is typically similar to a regular server, this component requires no further explanation. Non-user can still interact with our system through a smart trash bin, whereas a waste disposal tracker can only be used by registered users.

\section{A. Smart Trash Bin}

Our smart trash bin can be seen in Figure 1 where its internal structure can be seen in Figure 2. Each smart trash bin consists of 6 components, which are trash bin, LCD screen, speaker, Raspberry Pi 3, ultrasonic sensor, and additional component. LCD screen, speaker, and ultrasonic sensor are connected to Raspberry Pi 3, which is placed at the rear side of the trash bin. Moreover, all cables are connected through an artificial hole, which can be seen in Figure 3. An ultrasonic sensor placed at the uppermost part of the trash bin is utilized to detect open trash lid and available space in the trash bin. However, since the ultrasonic sensor is less sensitive to detect opened trash lid due to lid size and sensor position, an additional component is pasted on the trash lid to reach the ultrasonic sensor more easily. This component is made from styrofoam and pasted using double tape. Trash lid and ultrasonic sensor position when detecting opened trash lid can be seen in Figure 4 


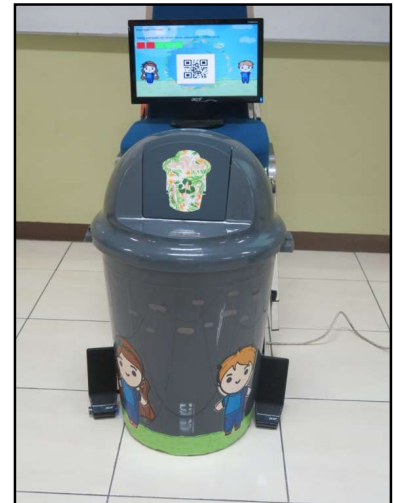

Fig. 1. Smart Trash Bin Layout

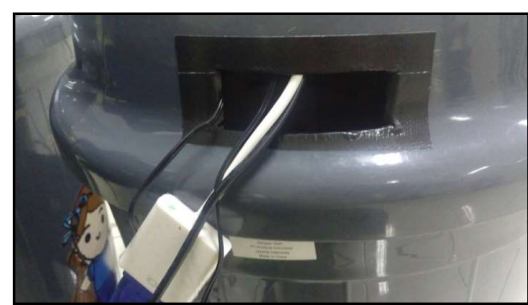

Fig. 3. Artificial Hole on Smart Trash Bin

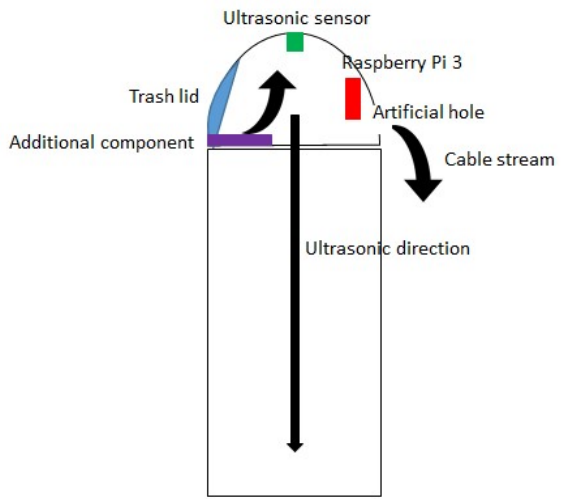

Fig. 2. Smart Trash Bin Internal Structure
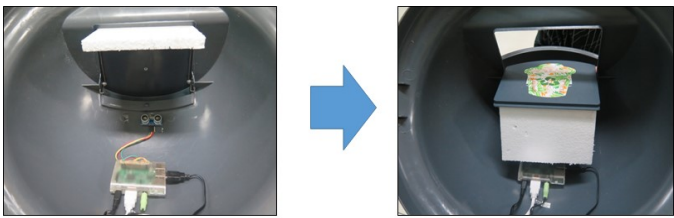

Fig. 4. Trash Lid and Ultrasonic Sensor Position When Opening Trash Lid

From a feature perspective, our smart trash bin consists of four features, which are an attractive design, appealing sound effect, trash-o-meter, and interactive waste disposal data addition. An attractive design is themed with a natural environment to attract people and give reflective visualization about unpolluted nature. Appealing sound effects will be played each time trash lid is opened, and it will be selected randomly from our provided sound effects (which consist of 18 sound effects that vary from explosion sound to human scream). Trash-ometer is intended to show available space in a smart trash bin without opening the lid. This feature is implemented as a solution from Q3 pre-survey problem, which concludes that most people are disappointed when they open trash bin lid only to see that it is already full. Available space is determined based on the distance between the uppermost part of the trash bin with the top of the waste heap. This distance is measured with (1), which is based on the ultrasonic sensor. $t$ is the time needed for an ultrasonic wave to reach the top of the waste heap and return to sensor generator, $e$ is $t$ when the smart trash bin is empty, and $f$ is $t$ when the smart trash bin is full. In our case, $e$ is assigned as 25 milliseconds, whereas $f$ is assigned as 100 milliseconds. After calculated, its result will be displayed as a percentage and visual bar on the LCD screen.

$$
\operatorname{availableSpace}(t)=100-((t-e) /(f-e))
$$

Even though most smart trash bin features can be used by the public, interactive waste disposal data addition is only limited for registered users. This mechanism is intended to count disposed waste automatically by the following flowchart given in Figure 5. The user is required to select an "interactive waste disposal" menu on his/her waste disposal tracker and scan the QR code provided on the LCD monitor. After synchronized, QR code in LCD screen will be replaced with a 10-seconds countdown timer, which represents time provided to dispose of waste. When countdown timer turns to 0 , the number of disposed waste will be sent to our server, and a new 
QR code will be generated on an LCD screen. Since our system assumes that the user will only throw one waste each time the trash lid is opened, the number of disposed waste can be counted by calculating how many times the trash lid is opened. Based on our observation, the ultrasonic wave provided by our sensor will return at 15 milliseconds or lower each time the trash lid is opened. Thus, the waste counter will be added by one each time our sensor returns 15 milliseconds or lower.

\section{B. Waste Disposal Tracker}

Our proposed waste disposal tracker is inspired from Fitbit that record user daily activity [13]. Yet, our application is focused on waste disposal volume instead of physical health. This application intends to reduce waste disposal volume by enhancing user awareness about personal waste disposal behavior. Personal waste disposal data is not only recorded but also compared with the community. Additionally, it also warns the user when they dispose of waste more than the community. For our initial contribution, the community is represented as survey respondents from a preliminary survey. As stated in the preliminary survey, respondents dispose of waste about 5 to 10 per day, wherein 2.405 to 6.405 of them are disposed on our development environment.

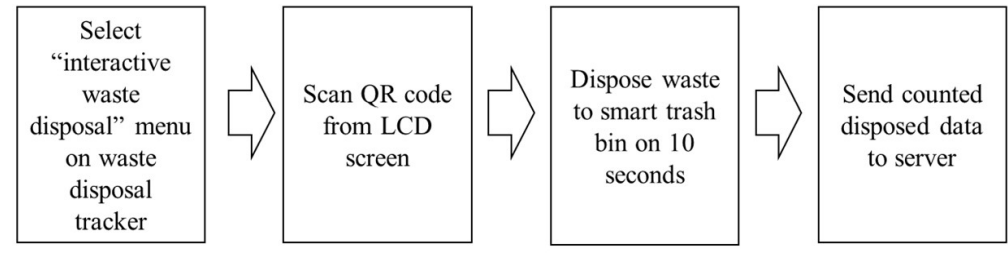

Fig. 5. Interactive Waste Disposal Flowchart

Since our waste disposal tracker targets the public in general, its layout and navigation are designed as simple as possible. As we know, elders may experience difficulties when adapting to complicated layout and navigation. The main screen of our waste disposal tracker can be seen in Figure 6 where the user name is displayed at the top of the page (we use "Oscar Karnalim" as a sample name). Furthermore, since our application is developed in Indonesia, we utilize the Indonesian language instead of English. User can utilize several features which are disposing of waste, viewing daily statistics, viewing achievements, and common user-based features (e.g., login and change password).

When a user selects "disposing waste," the user can select whether they dispose of a smart or regular trash bin. If a smart trash bin is selected, it will follow the flowchart provided in Figure 5. Otherwise, it will be navigated to manual waste disposal, where users need to input how much waste they have disposed of.

Daily statistics can be viewed by giving the number of elapsed day and waste disposal type as its input. The waste disposal type is determined based on the targeted trash bin type. It is categorized as "all disposed waste," "only waste disposed on smart trash bins," and "only waste disposed on regular trash bins." After inputted, a daily statistic of the given waste disposal type for the selected date range will be shown as a bar chart. For example, if user input 5 as the number of elapsed day and "all disposed waste" as waste disposal type, it will show daily statistics from the previous five days until today as a bar chart. The sample view of daily statistics can be seen in Figure 7 where each bar is colored based on daily disposed waste volume behavior. Red represents volume higher than upper bound of community-based waste disposal volume; yellow represents the volume in safety range of community waste disposal volume, and the green represents less than lower bound of community waste disposal volume. Community waste disposal volume is determined based on threshold defined from the preliminary survey. "all disposed waste" and "only waste disposed on regular trash bins" thresholds are defined as 5 to 10 whereas "only waste disposed on smart trash bins" thresholds are defined as 2 to 6 (both constants are truncated from preliminary survey result). "only waste disposed on regular trash bins" thresholds are set similar with "all disposed waste" thresholds since most users will dispose waste more frequently on regular trash bin instead of smart trash bin. As we know, smart trash bin coverage is limited. 


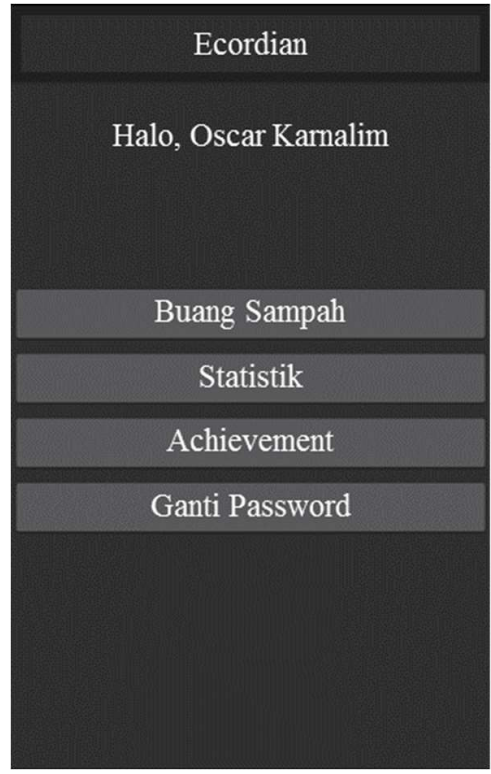

Fig. 6. Waste Disposal Tracker Main Screen

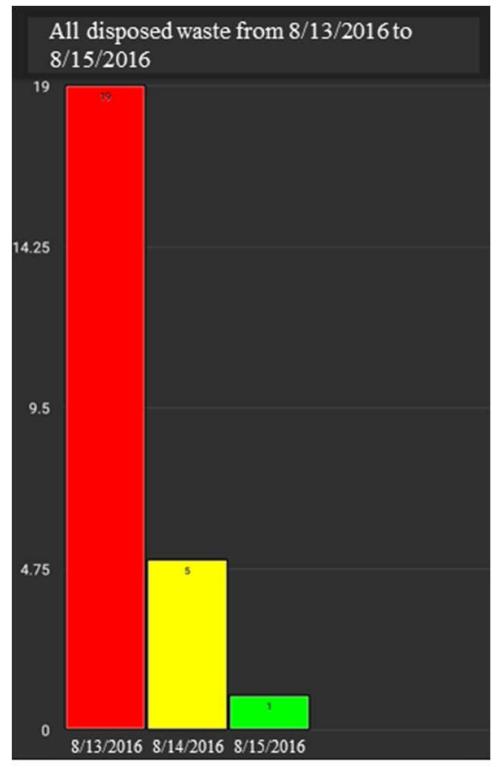

Fig. 7. Sample View of Daily Statistic

Beside playful and reflective experience, our waste disposal tracker is also featured with gamification that is implemented as hidden achievements and points. Points are gained by summing all achievement scores wherein achievement scores are varied based on their difficulties. These summed points then are utilized as a measurement for user skill where higher points may represent a more skilled user. Hidden achievements are implemented based on three motives which are: encouraging users to reduce their daily waste disposal volume, encouraging users to keep using our application, and penalizing wrong behavior. The second motive is intended for maintaining the number of users, whereas the third one is intended to warn users when they behave wrongly. For our initial work, our waste disposal tracker had applied 15 achievements, which subset for each motive can be seen in Table IV. Even though most achievements yield positive points, achievements in the third category yield negative points since they are utilized to penalize users that behave wrongly.

TABLE IV

THE SUBSET OF APPLIED ACHIEVEMENTS

\begin{tabular}{llll}
\hline \multicolumn{1}{c}{ Motive } & Achievement Name & Point & Task \\
\hline $\begin{array}{l}\text { Encouraging user to } \\
\text { reduce their waste } \\
\text { disposal volume }\end{array}$ & Safety First & 5 & Waste disposing volume is on safety zone for three days in a row \\
$\begin{array}{l}\text { Encouraging user to keep } \\
\text { using our application }\end{array}$ & First-timer & 15 & Viewing daily statistics for ten days in a row \\
$\begin{array}{l}\text { Penalizing wrong } \\
\text { behavior }\end{array}$ & $\begin{array}{l}\text { Heavy Trasher } \\
\text { Are you a cheater? }\end{array}$ & 20 & $\begin{array}{l}\text { Open waste disposal tracker for the first time } \\
\text { Disposing waste from } 18.00 \text { to } 23.59 \text { for five days in a row } \\
\text { Waste disposing volume is higher than upper bound of safety zone } \\
\text { for three days in a row } \\
\text { Disposing more than } 10 \text { waste in one QR code session }\end{array}$ \\
\hline
\end{tabular}




\section{RESUlTS AND DISCUSSION}

Evaluation is conducted using a survey that is given to 33 undergraduate students from the Faculty of Information Technology, Maranatha Christian University (26 males and 7 females). Each respondent is asked to give their opinion about several statements in 5-point Likert scale (1 represents strongly disagree, and 5 represents strongly agree). However, in order to yield more objective results, each respondent can only give their opinion after all system features have been demonstrated to them.

The detail of our survey and its result can be seen in Table V. S1-S7 are utilized for measuring the impact of system features when getting disposed waste on proper places; S8-S14 are utilized for measuring the impact of system features when reducing waste disposal volume, and S15-S16 are utilized for measuring the impact of the overall system toward our assumed problems on the preliminary survey. The first two statement categories are based on waste disposal management goals. As seen in Table V, seven statements are tended to be agreed by our respondents (average result $\geq 3.5$ ), whereas the rest of the statements are agreed (average result $\geq 4$ ). Thus, it can be concluded that our proposed system has achieved its purposes in general.

TABLE V

EVALUATION SURVEY

\begin{tabular}{|c|c|c|}
\hline ID & Statement & Average Result \\
\hline $\mathrm{S} 1$ & Overall system is effective for getting disposed waste on proper places & 4.303 \\
\hline $\mathrm{S} 2$ & Attractive design on smart trash bin is effective for getting disposed waste on proper places & 3.787 \\
\hline S3 & $\begin{array}{l}\text { Appealing sound effect on smart trash bin is effective for getting disposed waste on proper } \\
\text { places }\end{array}$ & 3.696 \\
\hline S4 & $\begin{array}{l}\text { Interactive waste disposal data addition on smart trash bin is effective for getting disposed } \\
\text { waste on proper places }\end{array}$ & 4.303 \\
\hline S5 & $\begin{array}{l}\text { Daily statistic of waste disposal volume on waste disposal tracker is effective for getting } \\
\text { disposed waste on proper places }\end{array}$ & 3.727 \\
\hline S6 & $\begin{array}{l}\text { Manual addition of waste disposal volume on waste disposal tracker is effective for getting } \\
\text { disposed waste on proper places }\end{array}$ & 3.757 \\
\hline S7 & $\begin{array}{l}\text { Achievements and points on waste disposal tracker is effective for getting disposed waste on } \\
\text { proper places }\end{array}$ & 4.151 \\
\hline S8 & Overall system is effective for reducing waste disposal volume & 4.151 \\
\hline S9 & Attractive design on smart trash bin is effective for reducing waste disposal volume & 3.636 \\
\hline $\mathrm{S} 10$ & Trash-o-meter on smart trash bin is effective for reducing waste disposal volume & 4.000 \\
\hline S11 & $\begin{array}{l}\text { Daily statistic of waste disposal volume on waste disposal tracker is effective for reducing } \\
\text { waste disposal volume }\end{array}$ & 3.848 \\
\hline $\mathrm{S} 12$ & $\begin{array}{l}\text { Manual addition of waste disposal volume on waste disposal tracker is effective for reducing } \\
\text { waste disposal volume }\end{array}$ & 3.848 \\
\hline S13 & $\begin{array}{l}\text { Achievements and points on waste disposal tracker is effective for reducing waste disposal } \\
\text { volume }\end{array}$ & 4.272 \\
\hline S14 & $\begin{array}{l}\text { Color warning shown on daily statistic in waste disposal tracker is effective for reducing } \\
\text { waste disposal volume }\end{array}$ & 4.090 \\
\hline $\mathrm{S} 15$ & Our proposed system attracts user to do waste disposal management activity & 4.333 \\
\hline S16 & Trash-o-meter can prevent people for disposing waste on full trash bin & 4.151 \\
\hline
\end{tabular}

When getting disposed of waste in proper places, interactive waste disposal data addition is agreed to be the most impactful feature. Most respondents claim that this mechanism is attractive and unique to encourage them to dispose of the waste on a smart trash bin. However, appealing sound effects yield the lowest one (even its score is still higher than 3.5) since sound effects may not be suitable in several quiet environments such as the library and study hall.

When reducing waste disposal volume, achievements, and points are considered to be the most impactful features by our respondents. They claim that achievement details and task enhance their awareness about their disposed waste and encourage them to reduce their personal daily waste disposal volume. In addition, the daily 
statistic of waste disposal volume (S11) and its color warning (S14) also yield positive impact since both statements are tended to be agreed by our respondents (3.848 and 4.090). On the other hand, attractive, smart trash bin design is considered to be the least impactful feature for reducing waste disposal volume. This result is reasonable since attractive design about the natural environment only affects in an implicit manner toward reducing waste disposal volume. Based on an overall system perspective, our proposed system achieved both waste disposal management goals. This statement is concluded based on S1, and S8 survey results in that yield an average score higher than 4 (respondents agree that our system achieves both goals in general).

S15 and S16 are asked to check whether our proposed system has been successfully covering assumed problems defined on a preliminary survey. S15 checks the importance of an attractive mechanism for handling Q1 and Q2 problems whereas S16 checks whether trash-o-meter can handle Q3 problems. Since S15 and S16 yield score higher than 4.0, thus it can be concluded that our assumed problems have been solved by our proposed system.

\section{CONCLUSION}

In this paper, a persuasive system for managing waste disposal had been proposed. It aims to achieve two goals, which are getting waste on proper places and reducing waste disposal volume. Based on our evaluation, all features implemented in our proposed system have a positive impact on achieving both goals. Moreover, our system also handles several problems such as incapability of moral background to encourage people to dispose of waste on the trash bin, boring and monotonous waste disposal activity, and discouragement for disposing of waste due to the full trash bin. The first two problems are handled with an attractive mechanism, whereas the latter one is handled by trash-o-meter.

For future research, we will measure the scalability and sustainability of our proposed persuasive system so that our system can be deployed in various circumstances. In addition, we also intend to measure the correlation between moral background and two major goals stated in waste disposal management. As implicitly stated in Q1 proposed problem, the moral background is assumed to affect people's behavior about waste disposal activity. So, its effect should be measured scientifically.

\section{ACKNOWLEDGMENT}

The authors would like to thank Maranatha Christian University Bandung for funding this research as an annual research grant.

\section{REFERENCES}

[1] M. Tscheligi and W. Reitberger, "Persuasion as an ingredient of societal interfaces," in interactions Societal interfaces: solving problems, affecting change, New York, ACM, 2007, pp. 41-43.

[2] K. Seaborn and D. I. Fels, "Gamification in theory and action: A survey," International Journal of Human-Computer Studies, vol. 74, pp. 14-31, 2015.

[3] A. A. Gartland and P. Piasek, "Weigh your waste: A sustainable way to reduce waste," in CHI '09 Extended Abstracts on Human Factors in Computing Systems, 2009.

[4] I. Reif, F. Alt, J. D. Hincapie, K. Poteriaykina and J. Wagner, "Cleanly: trashducation urban system," in CHI'10 Extended Abstracts on Human Factors in Computing Systems, 2010.

[5] B. J. Fogg, "The six most powerful persuasion strategies," in PERSUASIVE 2006, 2006. 
[6] J. Berengueres, F. Alsuwairi, N. Zaki, S. A. Helli and T. Ng, "Gamification of a recycle bin with emoticons," in The 8th ACM/IEEE international conference on Human-robot interaction, Piscataway, 2013.

[7] "Bottle Bank Arcade Machine," [Online]. Available: http://www.thefuntheory.com/bottle-bank-arcademachine. [Accessed 0812 2009].

[8] "The World's Deepest Bin," [Online]. Available: http://thefuntheory.com/worlds-deepest-bin. [Accessed 0812 2009].

[9] E. Paulos and T. Jenkins, "Urban probes: encountering our emerging urban atmospheres," in The SIGCHI Conference on Human Factors in Computing Systems, New York, 2005.

[10] R. Comber, A. Thieme, A. Rafiev, N. Taylor, N. Kramer and P. Olivier, "BinCam: Designing for Engagement with Facebook for Behavior Change," in INTERACT 2013, Berlin, 2013.

[11] A. Thieme, R. Comber, J. Miebach, J. Weeden, N. Kramer, S. Lawson and P. Olivier, "'We've Bin Watching You" - Designing for Reflection and Social Persuasion to promote Sustainable Lifestyles," in The SIGCHI Conference on Human Factors in Computing Systems, New York, 2012.

[12] P. Lessel, M. Altmeyer and A. Kruger, "Analysis of Recycling Capabilities of Individuals and Crowds to Encourage and Educate People to Separate Their Garbage Playfully," in The 33rd Annual ACM Conference on Human Factors in Computing Systems, Seoul, 2015.

[13] "Fitbit Official Site for Activity Tracker," Fitbit, Inc, [Online]. Available: https://www.fitbit.com/. [Accessed 298 2016]. 